\title{
FORMAS DE DESIGUALDAD SOCIAL EN UNA SOCIEDAD EN TRANSFORMACIÓN. CÓRDOBA (ARGENTINA) A COMIENZOS DEL SIGLO XX
}

\author{
Beatriz Inés Moreyra (Coord.)*
}

Recibido: 15/07/2018//Aceptado: 06/09/2018

\section{Introducción}

El subcontinente latinoamericano, y Argentina en particular, se ha caracterizado a lo largo de su historia por generar formas de desigualdades sociales, económicas y culturales particularmente severas y persistentes, como la discriminación racial, étnica y de género, la diferenciación entre ciudadanos de primera y segunda categoría y la configuración de una modernización hecha sobre la base de una desigual distribución de los recursos y los ingresos. En las décadas recientes, se ha asistido al deterioro del mundo del trabajo, la segmentación del acceso a la protección social y la multiplicación de las brechas entre clases. Esto justifica y legitima la relevancia del estudio de la desigualdad como una variable significativa y distintiva. En efecto, el análisis de las desigualdades persistentes permite interrogar e interpretar los modos en los cuales, históricamente, distintas sociedades y culturas han reproducido, tolerado, ignorado e impugnado inequidades que han adquirido formas y dimensiones diferentes para asegurar su permanencia a lo largo del tiempo.

Paralelamente, la preocupación por las formas de desigualdad ha ganado centralidad en el universo académico, político y de la sociedad civil en las últimas décadas y ha dinamizado un debate más extenso acerca de las dimensiones, causas e institucionalización de las desigualdades. El creciente interés por este campo de la investigación socio-histórica ha ido acompañado por una reorientación de sus perspectivas analíticas. En efecto, el enfoque puramente económico dejó de ser exclusivo y excluyente y se complementó con investigaciones más amplias sobre las inequidades múltiples. Diversas disciplinas como la sociología, el derecho, la antropología cultural y social, la ciencia política, la geografía, la arqueología y la historia han contribuido al desarrollo de nuevas perspectivas teóricas y metodológicas que están generando nuevos

\footnotetext{
* Instituto de Estudios Históricos-Centro de Estudios Históricos “Prof. Carlos S. A. Segreti”, Investigadora Principal del Consejo Nacional de Investigaciones Científicas y Técnicas (CONICET), Argentina, moreyrabea@gmail.com
} 
y más complejos conocimientos inéditos. Así, la perspectiva clásica centrada en la clase y el estrato se amplió y se colocó un énfasis sobre factores tales como la cultura, el género y la etnicidad -entre otros-, a la vez que se afirmó la naturaleza complementaria e interdependiente entre los ejes de estratificación.

Es decir, se revalorizó una mirada multidimensional que consideró la desigualdad como una construcción histórica mediada por relaciones de poder, en la que se entrecruzan múltiples factores y participan numerosos agentes dotados desigualmente de poder (Gootenberg, 2004: 9-19; Reygadas, 2008: 18-19). Hay que incluir, por supuesto, la distribución del dinero y las mercancías, pero también de muchas otras cosas como la estima, el prestigio, el conocimiento, la salud, la seguridad, las libertades, las actividades altamente valoradas y el poder. La desigualdad está inextricablemente vinculada con las relaciones de poder que se establecen sobre la base de las asimetrías. Además, los procesos simbólicos constituyen un componente fundamental de la construcción de la igualdad y la desigualdad. Como expresa Reygadas (2008: 35), la distribución de los bienes y servicios nunca sigue una lógica "racional" culturalmente neutra, ni se ajusta al funcionamiento de un mercado perfecto, sino que pasa por los filtros de la cultura, cuyos procesos de valoración, clasificación, jerarquización y diferenciación inciden en la determinación de la cantidad y la calidad de los beneficios que cada individuo y cada grupo recibe en una sociedad.

Por otra parte, como la desigualdad es un fenómeno relacional, para comprenderla se requiere estudiar, de manera dialéctica, tanto los mecanismos que la generan como aquellos otros que la cuestionan y la limitan. Es importante resaltar que la dialéctica entre igualdad y desigualdad ha atravesado históricamente al mercado, al Estado y a la sociedad civil y en estas tres instancias se puede detectar la confrontación entre procesos generadores de desigualdad.

La desigualdad también es multidimensional porque se reproduce en diversas escalas. Por un lado, en el nivel microsocial, como diferencias de capacidades y recursos entre los individuos; por otro lado, en el nivel meso social, en tanto pautas asimétricas de relaciones en distintas instituciones y campos de interacción; y, por último, en el nivel macrosocial, mediante la configuración y reproducción de estructuras inequitativas. Además, estas dimensiones no son auto explicativas por sí mismas sino niveles interrelacionados cuya lógica se sedimenta en fenómenos particulares, dado que los "umbrales de tolerancia a la desigualdad" son específicos de cada época y región y se encuentran socio-históricamente construidos

En este contexto de producción en el que en cada sociedad y en cada época existen diferentes tipos, grados y factores de desigualdades y fronteras móviles en relación con los niveles de inequidades, este dossier se propone indagar diversas dimensiones y especificidades que este proceso revistió en Córdoba, en las primeras décadas del siglo XX, en tiempo de la modernización, bajo el dominio de nuevos grupos de poder, la consolidación del Estado y del mercado y la expansión del capitalismo exportador. Particularmente, los distintos autores han puesto el énfasis en visibilizar el comportamiento concreto de los sujetos históricos, sus experiencias vividas en una 
pluralidad de campos sociales y las formas de asociación, integración, discriminación y exclusión en las sociedades y culturas analizadas. La licitud de la delimitación se justifica si se tiene en cuenta que la desigualdad, aunque a veces se trate de una temática no explicitada y de una realidad no siempre fácil de asir, subyace prácticamente en el entramado social de todas las sociedades pretéritas.

El artículo de Loreta Giannone, "El acceso diferencial a los recursos: El agua potable en el noroeste de Córdoba, Argentina (1912-1930)", analiza la forma en que los actores vivencian, experimentan, interpretan y reproducen el desigual acceso a los recursos, bienes y servicios y cómo esa limitación estructural y regional condiciona el comportamiento, las prácticas y los mecanismos que articulan las relaciones entre los sujetos. Los casos analizados en este trabajo (Cruz del Eje y La Cumbre) revelan la heterogeneidad dentro de la tendencia más general de considerar al noroeste como una región de atraso y de franco estancamiento en sus variables económicas y de población. Al colocar la lente en las prácticas y en los vínculos que se construyen entre los sujetos, se observan dos niveles de desigualdad; por un lado, el derivado de las relaciones asimétricas de poder en función de la posición de los distintos agentes en la red y, por otro, se reconstruye la trama de significados que subyacía a la lógica del reclamo y las estrategias articuladas que dieron lugar a las tensiones, los mecanismos asimétricos de negociación y las resistencias que operaron en las diversas demandas.

Los trabajos de Beatriz Moreyra y Nicolás Moretti se insertan en el revival académico de los estudios dedicados a la prolífica heterogeneidad de tipos asociativos. Analizan las instituciones asistenciales no estatales como proveedoras de seguridades mínimas para la sobrevivencia de los grupos más vulnerables, y como espacios de reproducción de las desigualdades sociales en Córdoba entre los años 1900 y 1930, período permeado por los desajustes sociales que acompañaron a los avatares de la cuestión social. En la primera contribución, "Estado y sociedad civil en la construcción del campo social en Córdoba (Argentina) 1900-1930: asistencialismo y desigualdad social," se analiza cómo las características institucionales, los escasos recursos asignados, las prácticas, estrategias, relaciones y culturas asistenciales de los actores involucrados en el modelo benéfico asistencial fueron factores que contribuyeron a la reproducción de la desigualdad social al interior de las instituciones y, por ende, en el tejido social en su conjunto. Por su parte, en estrecha filiación con este trabajo, el artículo de Nicolás Moretti, "Infancia y desigualdad en la pedagogía social salesiana (Córdoba, Argentina) a comienzos del siglo XX", intenta dilucidar los niveles, alcances y significados de las formas de desigualdad que pueden rastrearse en el universo infantil a través del análisis particular de una institución protagónica en la atención de la infancia en condición de riesgo en la Argentina moderna como fue la Congregación Salesiana. En la vocación de incluir a los sectores populares, eje de la pedagogía social que le valió a los salesianos su reconocimiento en el campo educativo y asistencial, no solo en América Latina, el autor observa los modos en los que se reprodujeron y legitimaron las desigualdades sociales.

Finalmente, la desigualdad ha permeado todos los procesos y estructuras sociales, incluso aquellos vinculados a los espacios de ocio de la población, que también 
se han conformado como criterio de deslinde y diferenciación social. En ese marco, el trabajo de Franco Reyna, titulado "La desigualdad en las estructuras competitivas del fútbol profesional de Córdoba (Argentina) en la década del treinta”, estudia las prácticas e interacciones asimétricas que se desarrollaron entre los actores del universo deportivo en el marco del proceso de mercantilización de la sociedad del espectáculo. Desde una perspectiva institucional, el autor examina más concretamente las inequidades que se generaron entre clubes de fútbol profesional en la estructuración de su sistema de competencia, las cuales afectaron la igualdad de oportunidades desde la que debían partir los distintos competidores. El análisis efectuado permite revelar que estos desequilibrios, ideados por los clubes más poderosos a fines de optimizar el desarrollo del espectáculo deportivo, fueron el resultado de diferentes modalidades de apropiación y distribución de los recursos materiales y simbólicos en juego en la práctica. Sobre la base de relaciones de poder y capacidades acumuladas históricamente, unas pocas entidades institucionalizaron nuevas formas de desigualdad y exclusión sobre las menos favorecidas, acrecentando sus distancias deportivas y económicas entre ellas.

En síntesis, a través de los artículos se ha intentado contribuir a una comprensión más diferenciada de las desigualdades sociales, que tome en cuenta las interdependencias multidimensionales y regionales como una estrategia de fuerte potencial cognoscitivo para dar cuenta de la complejidad, la diversidad, las similitudes y las diferencias de las formaciones sociales. Al mismo tiempo, se espera que constituyan una herramienta útil para la internacionalización de algunas problemáticas centrales que jalonan la historia latinoamericana, aportando al debate contemporáneo sobre la transnacionalización de líneas teóricas y metodológicas sobre la desigualdad.

\section{Referencias bibliográficas}

Gootenberg, P. (2004). "Desigualdades persistentes en América Latina: historia y cultura". Alteridades 14 (28), 9-19.

Reygadas, L. (2008). La apropiación. Destejiendo las redes de la desigualdad. Barcelona: Anthropos. 